\title{
Architectural Culture as a Barrier to Urban Regeneration
}

\author{
IAN BENTLEY and GEORGIA BUTINA WATSON \\ Joint Centre for Urban Design \\ Oxford Brookes University \\ United Kingdom
}

\section{INTRODUCTION}

The importance of involving local residents and workers in the regeneration of run-down urban areas is now enshrined in UK central government policy, through such programmes as Estate Action and City Challenge. However, it is widely accepted that effective community involvement is difficult to achieve in practice; and it is clear that one of the reasons for this difficulty stems from the presence of cultural barriers between architects and local people. The presence and importance of these barriers has been confirmed by various practitioners' accounts (for example Thompson, 1988) and is consistently clear from the authors' own consultancy experience in tenant-consultation work with the Oxford Brookes University Urban Regeneration Consultancy (URC) in a variety of situations, over the last six years (Bentley, 1993).

In any search for more effective processes of design consultation, these problems of cultural conflict will have to be addressed. The first step must surely be to develop a more structured understanding of why the problems arise. The practical need for such an understanding has become apparent in our own consultancy work, and in developing a current programme of research which attempts to situate this work in a clearer theoretical frame (Bentley and Butina, "Regeneration of Social Housing", JCUD Oxford Brookes University, 1992, unpublished research proposal).

There is a wide range of literature which relates obliquely to this topic (Zeisel 1981, Lifchez 1987,) but a systematic review of the urban regeneration literature (Tunstall, Regeneration of Social Housing, JCUD Oxford Brookes University, 1993, unpublished research bibliography) has revealed no body of theory which deals specifically with the reasons why cultural conflicts arise in the arena of urban regeneration consultation. Our objective in this paper is to sketch out a theoretical framework for addressing this issue in research.

\section{METHODS}

The lack of architectural or urban regeneration literature on this topic leads us to search for appropriate frameworks in wider fields of social theory. In this broader context, it is clear that these problems of cultural conflict relate to a mass of theorising around the concept of ideology. Treatments of ideology, however, cover a broad spectrum (Eagleton 1991): within this varied field, which particular approach would be most fruitful for our purpose? Our search for an appropriate methodology has been guided by a number of informal observations we have made during our consultancy work.

First, it is clear that the cultural mores of the architects we have encountered are deeply held and actively valued. To give adequate emphasis to this dimension in our research, we need an approach which conceives of ideology as a medium which is actively used in the construction of individuals' subjectivities.

Second, we have found that the cultural mores of most architects seem to differ from those of other actors in the urban regeneration process; which suggests that the mores themselves are in some way related to working roles. However, it also seems to us that although architects who are willing to work with consultation have (to that extent at least,) cultural values which differ from those held by their "anti- consultation" peers, nevertheless the aspects of architectural culture which appear to militate against effective consultation appear precisely to be those which are shared with other, anti-consultation architects. This strongly suggests that these "conflict" mores must be directly linked to the "mainstream" role which architects typically play vis a vis the development process as a whole. To give adequate expression to this dimension, we need an approach to ideology which conceives it as a medium through which individuals become qualified to perform typical mainstream working roles.

Finally, we have found that many of the ideological conflicts we have encountered have taken a tacit form, in the sense that they have been embodied in practical working methods. Suggestions for changing these, to lessen the conflicts they engender, have typically been countered through economic arguments; such as the claim, for example, that it would not be financially viable to adopt more user-friendly methods of communication. To encompass this dimension, we need an approach to ideology which sees it as linked to economic factors. 
The particular tradition of theorising ideology which appears to fit most closely with the requirements outlined above is that developed by Goran Therborn (Therborn 1980). Ideology, as Therborn conceives it, is "that aspect of the human condition under which human beings live their lives as conscious actors in a world that makes sense to them" $(1980,2)$. The working situations which architects have to make sense of - and therefore the ideological structures through which they construct their particularly architectural subjectivities - have particular characteristics in the context of the capitalist development process. As Therborn sees it, the process through which agents are fitted into the status quo involves them coming to terms with three crucial aspects of the social organisation of production, none of which can be reduced to mere by-products of anything else. The first of these aspects concerns what Therborn calls "the mode of distributing the means of production, the channels of access to these and the barriers of separation" $(1980,55)$ In the specific terms of the capitalist urban transformation process, this is concerned with gaining access to development agencies, whether in the public or the private sectors: crudely put, how architects have to present themselves in order to be hired by developers. Since consultation work is financially only a small proportion of the overall field of work available to architects, we should expect important characteristics of "mainstream" architectural ideology to be strongly linked to the need to gain access to profit-orientated private-sector developers. The second important aspect of the social organisation of production is related to "the social relationships within and between the producers and the appropriators of surplus labour in the economic mode of production" $(1980,55)$ or, in more everyday language, what the various agents in the urban transformation process have to do once employed, in order to work within the constraints set by the development agencies which employ them, if they are not to lose their jobs. The third key aspect concerns "the objective or institutionalised orientation of production" $(1980,55)$ : what the urban transformation process is supposed to produce, in terms of the structural rules which define any agent's particular area of work.

According to Therborn, the ideological structures which both subject and qualify agents in these three crucial aspects of the social organisation of production operate through "telling them, relating them to, and making them recognise" three fundamental aspects of experience:
1. what exists, and its corollary, what does not exist: that is, who we are, what the world is, what nature, society, men and women are like. In this way we acquire a sense of identity, becoming conscious of what is real and true; the visibility of the world is thereby structured by the distribution of spotlights, shadows, and darkness.

2. what is good, right, just, beautiful, attractive, enjoyable and its opposites. In this way our desires become structured and normalised.

3. what is possible and impossible. Our sense of the mutability of our being-in-the-world and the consequences of change are hereby patterned, and our hopes, ambitions, and fears given shape. (Therborn, 1980, 18)

The need for architects to make sense of their working situations, through the medium of ideology, therefore involves them in defining their own relationship to the three aspects of the social organisation of the production of urban space outlined above, in terms of what exists, what is good and what is possible. This generates a matrix of nine potential ideological strategies which together constitute architectural culture, as sketched out below:

Each of these nine strategies can be embodied either in the way architects think and feel, or in their working methods at a tacit level, or in both.

Having generated this theoretical framework, we now have to investigate whether it is useful in practice. To what extent can it predict the ideological strategies deployed by designers in real urban regeneration situations? To answer this question in depth, we shall eventually carry out a series of structured case-studies in a range of regeneration situations. Before it is worth committing the necessary resources for this larger project, however, it is sensible to explore how far the theoretical framework can help us understand the ideological strategies we have encountered in our own practical work to date. That is what the rest of this paper is about.

\section{ANALYSIS OF CASE-STUDIES}

To make this preliminary exploration, we selected case study material from two examples of URC's consultancy work. These were chosen for three reasons. First, both of them centred around processes of resident and worker participation in the urban regeneration process. Second, they were very different in physical scale and context: the first was concerned with a large inner-London housing estate, whilst

\begin{tabular}{|l|l|l|l|}
\hline gaining access to development agencies & What is & What is good & What is possible \\
\hline working in development agencies interests & & & \\
\hline working for public benefit & & & \\
\hline
\end{tabular}


the second involved work on a district commercial centre in a Midlands town. Third, we had kept copious files on both projects, so documented data was readily available.

We began the analysis by reviewing the files on both projects. For resource reasons, we restricted our interest to verbal arguments, rather than including a review of practical techniques. Many letters and minutes from architects contained relevant material, and since we have been interested in the "cultural conflict" theme for several years, we had ourselves brought references to the topic into many meeting minutes and informal file notes. We therefore extracted these and highlighted key words and phrases; which we then categorised according to Therborn's distinction between definitions of "what is," "what ought to be" and "what is possible," in relation to architecture and to the architect's role in producing it. This exercise proved relatively straightforward, though several of our key phrases spanned across more than one of these categories, thus illustrating three obvious facts. First, the categories themselves, though far from arbitrary, are separated merely for analytical convenience: clearly, realworld ideologies can (and perhaps usually do) embody more than one strategy. Second, not all potential strategies will necessarily come into practical play in any given situation. Third, individual architects will have constructed particular subjectivities from the total ideological set available, and these differ one from another. We should like at this point to pay tribute (from our own ideological position) to those architects we have worked with who have contributed nothing (or almost nothing) to our keyword list.

The results of our preliminary categorisation showed a remarkable consistency of ideological strategies between the two projects, despite their different natures. The most common phrases are set out below:

\section{Definitions of what is}

Architecture is:

- the design of buildings

- a creative art, distinct from "building"

- something which cannot be rationally explained

Architects are:

- creative artists

- People with an expert perception of design quality

\section{Definitions of what ought to be}

Architecture ought to be:

- designed to a written, not a drawn brief

- not designed by committee

- something better than non-architects could imagine in advance

Architects ought to be:

- creative artists

- left free to decide the physical form implications of

"what people want"

- "responsible professionals," not "taking sides"

\section{Definitions of what is possible}

It is only possible for Architecture:

- to be produced by Architects (anything else would just be "building")
It is only possible for Architects:

- to work within their fees

- to work within the paying client's brief

Having organised our case-study material into these categorised lists, our next task was to link these to those key aspects of the social organisation of production - in this case, this production of the urban environment - which Therborn identified. Let us briefly outline those links which we find most interesting and important.

First, let us consider how this framework has helped us to see ideological strategies as linked to architects' need to gain access to development agencies: in mainstream architectural culture, in late twentieth-century Britain, mainly concerned with private-sector development. Given its fundamental importance to the economic survival of nearly all architects, it is not surprising that we found it easy to make links to many ideological strategies here.

As we see it, architects - increasingly under economic attack from all sorts of other professionals in the marketplace for design services - have progressively been led to identify their "unique selling proposition" in terms of their creative, artistic abilities: as yet, no-one else has laid claim to this. Hence the crucial importance of a network of closely-related ideological strategies - we have come to call this sort of network a "constellation" - around the concepts of "creative art/different from mere building/expert perception of quality/unable to be rationally explained/ better than non-architects could imagine in advance/not designed by committee." This constellation - let us call it the "creativity constellation" - is what presents architects as saleable in a highly competitive market, and it cannot therefore be abandoned lightly. From the point of view of effective consultation, of course, the creativity constellation is wildly counter-productive, because it works to maintain the survival of architecture as a discipline precisely though attempting to exclude others from joining in the process of physical design.

Having gained access to development agencies, of course, architects are constrained - primarily through financial sanctions - to be seen by those agencies to be working in their agencies' interests: again, since most development agencies operate in the private sector, we should expect mainstream architectural culture to be strongly linked to the interests of such patrons. In our interpretation, this link has a powerful role to play in explaining most architects' fixation on "the building" as the unit of design: "the building", after all, is what is traded in the marketplace.

A fixation on "the building" does not, however, adequately capture the way the local participants conceptualised the built environment in our case study material. The local participants were primarily interested in the emergent effects of the relationships between buildings - effects such as the perceived safety of the public realm - which can only be conceptualised weakly by architects who have a primary focus on the building as the unit of design.

Constrained to work in the paying patron's interests, which may often conflict with those of non-paying users, 
particularly in terms of the public realm, architects have to open up a conceptual space in which this potential conflict can be resolved in the development agency's interests. Hence the "freedom to operate" constellation: architecture should be designed to a written rather than a drawn brief, and architects should be left free to decide the physical form implications of "what people want". The fact that this ideological constellation is also related to the architect's need to gain access to development agencies in the first place, as we already saw, gives it a double importance in architectural culture.

We interpret the remainder of our categorised list of keywords as a set of ideological strategies for making sense of any conflict there may be between the need for architects to work in the development agency's interests, and the "institutionalised orientation of production": in this case, the general institutionalised claim that architects work for the public good. Here the definition of "good design" in absolute terms, rather than relative to particular interests, clearly works to absolve architects from having to take seriously other people's definitions of good design, whilst defining "the possible" in terms of working within fixed fee structures and paying clients' briefs absolves them from responsibility for going against community interests.

\section{DISCUSSION}

Making these links between ideological strategies and the social organisation of production was not difficult, but involved a great number of interpretative leaps. We are certainly not claiming that we have "got it right" - our point is merely that the analytical framework we have developed from Therborn's work has proved a fruitful tool for generating plausible hypotheses about the links between architectural culture and material factors concerned with the prevailing social organisation of space-production in the contemporary British development process.
In the light of our analysis, Therborn's theoretical framework does appear to present us with a useful tool for further research in this area; for it makes sense of all the ideological strategies we have encountered in our two very different situations. We should therefore expect it to have considerable predictive powers in the range of new case study situations which our future research will cover.

One potential shortcoming of the "matrix of strategies" approach however is that it tends to encourage its users to see these strategies as "separate things" rather than as complementary aspects of a total situation. This seems to be inherent in any attempt to analyse complex social phenomena, and our concern is only that the disaggregated form of the frame of reference may itself suggest "one to one" correspondences between ideological problems and their possible solutions, thereby running the risk that partial solutions to one aspect of the overall problem may lead to worse problems in other areas.

Because the emergent effects of the whole design culture are more weakly conceptualised than the effects of particular ideological strategies within it, it is important to see the matrix of strategies as a springboard for creative thinking rather than letting it become a straitjacket. Given that caveat, however, we see this framework as a powerful tool in the future research.

\section{REFERENCES}

EAGLETON, Terry, Ideology, an introduction, London, Verso, 1991.

LIFCHEZ, Rethinking Architecture, Berkeley, California, University of California Press, 1987.

THERBORN, Goran, The Ideology of Power and the Power of Ideology, London, Verso, 1980.

THOMPSON, John, "Community Architecture" in Urban Design Quarterly 28, pp29-34, September 1988.

ZEISEL, John, Inquiry by Design - Tools for Environment-Behaviour Research, Cambridge, University Press, 1981. 